\title{
Increasing evidence of low lymphatic filariasis prevalence in high risk Loa loa areas in Central and West Africa: a literature review
}

\author{
Louise A. Kelly-Hope*, Janet Hemingway, Mark J. Taylor and David H. Molyneux
}

\begin{abstract}
In West and Central Africa, there is a need to establish the prevalence of Wuchereria bancrofti in areas that are coendemic for Loa loa, in order to implement the appropriate strategies to scale-up interventions for the elimination of lymphatic filariasis (LF). Due to the risk of severe adverse events (SAES) to ivermectin in individuals with high L. loa microfilaraemia, the current strategy recommended by the World Health Organization (WHO) is twice yearly mass drug administration (MDA) with albendazole, supplemented by vector control targeting the Anopheles vectors. Defining $W$. bancrofti prevalence in areas co-endemic with $L$. loa is complicated by the cross-reactivity of rapid diagnostic immunochromatographic card tests (ICT), widely used for LF mapping, in individuals with high L. loa microfilaraemia. This has probably resulted in the overestimation of LF prevalence, triggering the implementation of MDA strategies, which may be unnecessary and wasteful of the limited resources for elimination programme implementation. Here we review the literature and present historical evidence, which uniformly highlight low or no prevalence of $W$. bancrofti infection and/or clinical LF cases across five Central African countries, in more than 30 different geographical areas covering 280 individual sites and > 22,000 individuals tested within high risk L. loa areas. This highlights the very limited information available on LF prevalence in L. loa areas, and potentially has major policy implications, which could shift the focus towards revised mapping criteria to verify low or no $W$. bancrofti prevalence in high risk L. loa areas. In this situation, revising the current WHO strategy from MDA, to focus more on ensuring high and effective vector control, through insecticide treated/long-lasting impregnated bednets (ITNs/LLINs), integration of point-of-care test-and-treat options into health systems, and consolidating closer links with the malaria control programme may be a more effective and appropriate use of the limited resources and drug donations available for LF elimination.
\end{abstract}

Keywords: Loa loa, Loiasis, Tropical eye worm, Chrysops, Vector control, Lymphatic filariasis, LF, Onchocerciasis, Neglected tropical diseases, NTDs, Africa, IVM, Integrated vector management

\section{Background}

Lymphatic filariasis (LF) is a disabling parasitic disease transmitted by mosquitoes [1]. It is targeted for elimination and is one of the five neglected tropical diseases (NTDs) that are primarily controlled by preventive chemotherapy. The Global Programme to Eliminate LF (GPELF) has worked towards elimination for nearly two decades; first by interrupting transmission with mass drug administration (MDA) using different regimen

\footnotetext{
* Correspondence: Louise.Kelly-Hope@|stmed.ac.uk

Liverpool School of Tropical Medicine, Liverpool L3 5QA, UK
}

combinations of albendazole, ivermectin and diethylcarbamazine (DEC), and second by alleviating suffering through morbidity management and disability prevention (MMDP) $[2,3]$. Overall significant progress has been made towards elimination, but greater efforts are required in many countries in the World Health Organisation (WHO) African Region, where many countries remain behind the elimination targets [4].

In 2016, the African region was estimated to have 371.2 million people requiring MDA across 32 endemic countries, with a reported coverage of $56.9 \%$ [3]. While this marks an increase in coverage from previous years,

(c) The Author(s). 2018 Open Access This article is distributed under the terms of the Creative Commons Attribution 4.0 International License (http://creativecommons.org/licenses/by/4.0/), which permits unrestricted use, distribution, and reproduction in any medium, provided you give appropriate credit to the original author(s) and the source, provide a link to the Creative Commons license, and indicate if changes were made. The Creative Commons Public Domain Dedication waiver (http://creativecommons.org/publicdomain/zero/1.0/) applies to the data made available in this article, unless otherwise stated. 
there are still 17 African countries yet to start or scale-up MDA to full nationwide geographical coverage. The reasons for limited coverage are complex [5] and related to several factors including - but not limited to political will, conflict, financial commitment, technical support, difficult to access populations, stakeholder interest, poverty, poor infrastructure, limited human capacity, competing priority diseases, and co-endemicity with the filarial parasite Loa loa, which causes the disease known as Tropical eye worm or loiasis.

Loa loa occurs in 10 countries in Central and West Africa (Fig. 1a) [6] and poses two problems for LF elimination. First, the use of ivermectin presents a risk of severe adverse events (SAEs) to individuals with high $L$. loa parasitaemias, i.e. > 30,000 microfilariae (Mf) per millilitre blood, and can induce encephalopathy, coma and death $[7,8]$; secondly by complicating the mapping of LF distribution as the standard rapid antigen diagnostic tests for LF [e.g. BinaxNOW Filariasis immunochromatographic test (ICT) and/or the new Alere Filariasis Test Strip (FTS Alere, Scarborough, ME, USA)] [9], cross-react with $L$. loa, resulting in false positives for Wuchereria bancrofti, with strong associations between ICT positivity and L. loa Mfs [10-13], e.g. around 30\% and $50 \%$ of ICTs reacting to L. loa when densities were $>15,00 \mathrm{Mf} / \mathrm{ml}$ and $>30,000 \mathrm{Mf} / \mathrm{ml}$ respectively [13].

The WHO recommends an alternative strategy for LF elimination in $L$. loa co-endemic areas, including twice yearly MDA with albendazole supplemented with vector control, primarily insecticide-treated/long-lasting bednets (ITNs/LLINs), which control Anopheles mosquitoes that transmit both LF and malaria [14]. In addition, a basic five step model for national LF programmes to work at implementation unit level has been developed to supplement the WHO guidelines and help initiate treatment plans [15]; however, countries are still struggling to implement the strategy. This is complicated by the lack of clarity on the extent of LF prevalence and evidence that $W$. bancrofti transmission is absent or low in countries with high risk of $L$. loa, such as Cameroon and Gabon [3, 16, 17]. This raises questions on how to accurately map LF in high risk $L$. loa areas and whether LF MDA in these areas is warranted.

Here we review existing literature on $W$. bancrofti prevalence in high risk $L$. loa areas, to highlight the extent of W. bancrofti-L. loa co-endemicity. This may further help to refine the needs of national programmes, and current WHO strategies $[14,15]$.

\section{Geographical area and search strategy}

High risk $L$. loa areas were defined as those with > 40\% loiasis prevalence determined by the Rapid Assessment Procedure for Loiasis (RAPLOA) [18, 19], which correlates to $20 \%$ Mf prevalence and high risk of SAEs (Fig. 1a). The geographical high risk $L$. loa areas and the risk of LF prevalence mapped within these parameters are highlighted in Fig. 1b.

A literature search and collation of data was conducted using PubMed, JSTOR, SCOPUS and Google online sources. Search terms, and combinations thereof, included Wuchereria bancrofti, lymphatic filariasis, elephantiasis, Loa loa, loiasis, and tropical eye worm. Further sources of information were found within reference section of documents. Due to the cross-reactively problem associated with antigen tests, studies only using these tests to determine LF endemicity were excluded.

\section{Evidence from the existing literature}

In total, 16 documents with information on LF prevalence in humans in high risk $L$. loa areas were found between 1928 to 2018. The documents ranged from historical review articles with anecdotal reports, conference abstracts to specific research articles. Most documents with specific data were from Cameroon, Gabon and DRC, and are summarised below and in Table 1.

\section{a Loiasis prevalence}

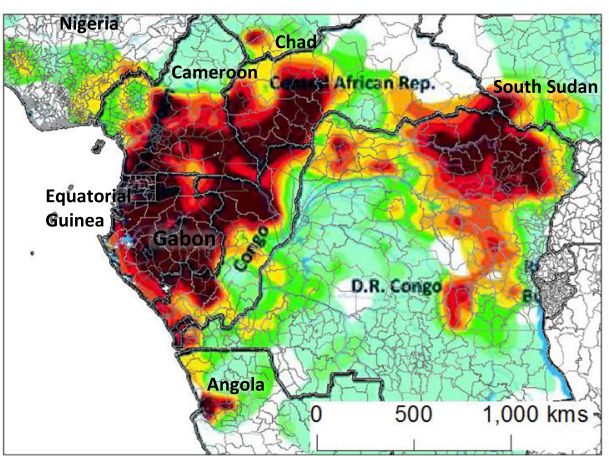

\section{b Loiasis high risk and LF low risk}

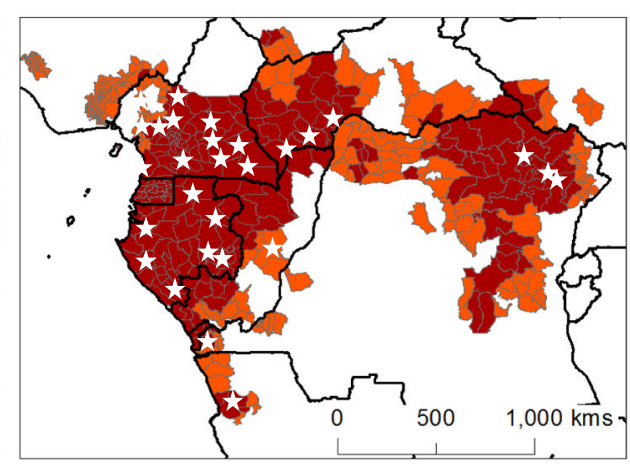

Loiasis high risk

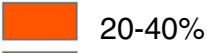

$>40 \%$

LF low risk /absence

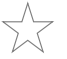

National boundaries

Country

Sub-national

Fig. 1 Maps of loiasis prevalence and study areas with low LF risk. a Loiasis prevalence. b Loiasis high risk and LF low risk 
Table 1 Summary of studies examining Wuchereria bancrofti human infection

\begin{tabular}{|c|c|c|c|c|c|c|}
\hline Country & $\begin{array}{l}\text { Study } \\
\text { year }^{\mathrm{a}}\end{array}$ & Province/District & Diagnostic & $\begin{array}{l}\text { Number of } \\
\text { sites }\end{array}$ & $\begin{array}{l}\text { Number } \\
\text { sampled }\end{array}$ & Reference \\
\hline Angola & 2015 & Bengo Province & Clinical & 29 & 2017 & [20] \\
\hline \multirow[t]{2}{*}{ DRC } & 2013 & Oriental Province & Mf & 30 & 2724 & [10] \\
\hline & $1974^{a}$ & Mayombe, Bas Congo Province & Mf & 32 & 2476 & [22] \\
\hline \multirow[t]{9}{*}{ Cameroon } & 2018 & East, Central, South, Littoral & $\begin{array}{l}\text { Clinical; Mf; Wb123; } \\
\text { qPCR }\end{array}$ & 29 & $4698(24)^{c}$ & [23] \\
\hline & $2017^{b}$ & $\begin{array}{l}\text { South, Central, South-east, North West, Far } \\
\text { North }\end{array}$ & Wb123; qPCR & 50 & 5000 & [16] \\
\hline & 2016 & East, Central, South, Littoral & Mf & 31 & $14,577(185)^{c}$ & [17] \\
\hline & 2016 & Messok District, Haut-Nyong Department & $\mathrm{qPCR}$ & 8 & 1085 & [24] \\
\hline & 2013 & Lolodorf surrounds & Wb123; qPCR & 26 & 1812 & [13] \\
\hline & 2013 & East, North-west, South-west & Mf; Clinical & 42 & $2190(24)^{c}$ & [11] \\
\hline & $1990^{\mathrm{a}}$ & Goura, Badissa Nyamanga & Mf & 3 & 1324 & {$[25,29]$} \\
\hline & 1975 & Department Mifi & Mf; Clinical & 6 & 1004 & {$[25,28]$} \\
\hline & $1957^{\mathrm{a}}$ & Yoko Region & Mf & 1 & 50 & $\begin{array}{l}{[25,27,} \\
36]\end{array}$ \\
\hline Total & & & & 287 & $38,957(22,399)^{d}$ & \\
\hline
\end{tabular}

Indicates publication year, when study year is not stated

${ }^{\mathrm{b}}$ The exact numbers in the high risk Loa areas is unclear until publication i.e. the North, West, far West have minimal or no overlap with high risk areas, and therefore related numbers are likely not to count

'Indicates the number of individuals initially examined for clinical conditions or using ICT or FTS (with positive cases examined further using different diagnostic tests)

${ }^{d}$ Indicates total number of individuals examined (total number excluding ICT or FTS)

\section{Angola}

In 2014, a micro-mapping clinical survey was conducted in Bengo Province in the northern region of Angola including 2017 individuals from 29 communities. Clinical cases of LF were confirmed by medical officers. Eight individuals had limb lymphoedema $(0.4 \%)$ and 20 men had hydrocoele $(2.6 \%)$ [20]. While clinical cases do not necessarily represent recent transmission, nor define endemicity, the relatively low numbers are in line with historical surveys in the same region in the 1960s [21], and highlight the probable distribution of isolated foci of $W$. bancrofti in northern Angola, with endemic zones in Cabinda District and the northern region of Zaire District.

\section{Democratic Republic of the Congo}

In 2011-2013, a seroprevalence survey was conducted in 30 villages in the Oriental Province in eastern DRC including 2724 individuals (aged $\geq 14$ years) from the Ituri region (Mambasa Territory) and Haute Uele region (Watsa Territory) [10]. The presence of W. bancrofti was assessed by examining night blood slides for Mf by microscopy and parasite DNA by quantitative real-time polymerase chain reaction (qPCR). Only one individual was positive for $W$. bancrofti DNA.

In 1974, a study in 32 villages in the Mayumbe region on the western coast of DRC, close to the mouth of the Congo River, including 2476 adult individuals who had lived in that region for at least 5 years. Only one village was positive for $W$. bancrofti by night blood slide Mf microscopy [22].

\section{Cameroon}

In 2017, two studies from Cameroon highlighted the absence of $W$. bancrofti in $L$. loa endemic areas [16, 17]. Wanji et al. [16] reported a seroprevalence study of 5000 individuals from 50 villages across the South, Central, South-east, North-west, Far-north areas of the country, which detected no W. bancrofti positivity using two different antibody Wb123 tests, examining night blood slides for $\mathrm{Mf}$ and confirming selected samples with pPCR methods. Similarly, Biholong et al. [17] reported on a seroprevalence study conducted in 2010-2012 of 14,577 individuals (aged $\geq 9$ years), across 31 health districts which detected no W. bancrofti Mf by night blood slide in 185 of the 235 individuals who were initially found to be antigen-positive using FTS.

In 2016, a study examining the geographical distribution of podoconiosis using parasitological, serological and clinical evidence to exclude the causes of lymphoedema, including LF was conducted across ten Regions of Cameroon. In the four high risk $L$. loa regions, i.e. the Central, East, Littoral and South Regions, a total of 4698 people from 29 communities were examined. In total 24 lymphoedema cases were found in these four Regions, and of these one was FTS-positive (Littoral Region) and none were positive by Mf, Wb123 and qPCR test [23]. 
Additional findings in 2013 and 2016 suggested no LF. These included a seroprevalence study in eight villages in Messok District [24], including 1085 individuals (the majority aged $>15$ years) in 2016, and a seroprevalence study in 26 communities within $50 \mathrm{~km}$ of Lolodorf, southern Cameroon, including 1812 individuals (aged $\geq$ 5 years) in 2013 [13]. The absence of $W$. bancrofti was confirmed by qPCR and $\mathrm{Wb} 123$ assays in 52 individuals initially found to be antigen-positive using ICTs. All other ICTs were negative.

Another seroprevalence study in 42 communities in the East, North-west and South-west of the Cameroon rainforest belt, including 2190 individuals (aged $>10$ years) in 2013, found no W. bancrofti Mf by night blood slide in 24 individuals that were antigen-positive using ICTs. Twenty cases of lymphoedema were found and none of them were ICT-positive. No cases of hydrocele were found.

A review by Boussinesq in 1999 [25], of historical studies published in French, highlighted that in 1928, Sharp [26] found very low W. bancrofti Mf prevalence 0.4-2.0\% in Mamfe region; in 1957, Languillion [27] reported no W. bancrofti Mf in 50 individuals from Yoko region; in 1975, Brengues [28] reported no W. bancrofti filaria in six localities in the Department of Mifi including 1004 individuals, and 32 cases of elephantiasis among 2395 individuals clinically examined; in 1990, Lochouarn [29] found no W. bancrofti Mf in three villages, Goura (Department du Mbam et Kim), Badissa and Nyamanga (Mbam et Inoubou) including 1324 individuals (aged $>10$ years).

\section{Excerpts from historical and/or anecdotal reports}

While rigorous data on LF distribution in L. loa areas is limited, there are many anecdotal and historical reports that W. bancrofti across Central Africa is low or absent. These are presented here as excerpts with the approximate decade and country of the review, study or publication to provide perspective on time frame and place.

"W. bancrofti is said not to be found from the Uele river in the Belgian Congo to the Coast or from the Ouham river to Gabon. Nor has it been found in Gabon, according to Galliard. At M'Bomou (a head tributary of the Ubangui river), W. bancrofti was not found in 400 night bloods, although elephantiasis occurs; this is said to be due to Onchocerca."

( 1910-1950s; Gabon) [30-32]

"... elephantiasis, on the contrary, is rather rare and a very limited distribution" ( 1910s; French Equatorial Africa) [32]

"In the Cameroons, we have never found the microfilariae in night surveys in five large villages in the rainforest, not during the day in many thousands of bloods films. Elephantiasis only occurs in the rainforest where infection with O. volvulus is found."

(1950s; Cameroon) [30]

"It has never been encountered in many thousands of similar blood films taken in the Cameroons."

( 1950s; Cameroon) [33]

"In most of Belgian Congo, however, filariasis seems to be rare and unimportant."

( 1950s; Belgian Congo) [30]

"... in 1924, an extensive investigation into the incidence of infection by L. loa and A. perstans, and found that the percentage of population infection with $L$. loa was 17 , with $A$. perstans 77 , and with $F$. bancrofti only 0.4." ( 1920s; Cameroon) $[26,30]$

"In Ayos, W. bancrofti is never seen." ( 1930s; French Cameroons) [30]

"In the Bankim district, located in the Tikar plain, the 10 surveyed villages were all hyperendemic for loiasis.... The low prevalence of hydroceles suggests that lymphatic filariasis is not endemic in this study area." ( 2000s; Cameroon) [34]

"According to Languillon (1957) the microfilaria rate is 16\% in the savanna region of the north (Diamare and Benoue), but falls to $0.8 \%$ in the forest zone of the south..." (1950s; Cameroon) [27, 35]

"Infection with W. bancrofti is considered to be slight but there is little evidence on the subject (Hamon et al. 1967). Brumpt et al. (1972) who examined 100 persons in two small villages in the north near the Chad frontier, detected one case of infection with this parasite." (1960s; Central African Republic) [35-37]

"... In the western region of Nigeria, with special reference to the Ibadan area, $W$. bancrofti was very rare in this region. ... On the other hand, Ibadan lies in the heart of the Loa belt of West Africa and its infection there is common." ( 1970s; Nigeria) [38]

"For the Gabonese population one can approximately say that 3 out of 5 adult patients have filariasis, two being D. perstans and one L. loa. Consequently, these affections represent a major public health problem. Finally, one must note that no cases of lymphatic filariasis has been identified."

( 1980s; Gabon) [39]

"Because only a few infections were identified across Gabon ... undergoing remapping to determine whether MDA for LF is warranted," ( 2010s; Gabon) [3]

\section{Conclusions}

This review highlights the very limited information available on LF prevalence in $L$. loa areas. The data that are available are consistent with anecdotal historical reports indicating that LF is very low or absent in high risk $L$. loa areas. The distinct ecological niches of the filarial parasites and their various vectors may explain these 
differences, i.e. Anopheles species transmitting W. bancrofti may prefer savanna-like habitats more than the deep forested ecology, where the L. loa vector Chrysops species thrive, and there may be competitive exclusion, given the co-endemicity of five human filarial parasites in these countries [40]. Regardless, these findings have major implications for co-endemic countries, and GPELF, and may significantly reduce the need for MDA for millions of people across vast geographical areas of Central and West Africa as noted recently in Cameroon $[16,17]$, with consequent resource implications. It is important that further confirmatory mapping is conducted, with appropriate population-based sampling strategies, including individuals over five years of age. Sentinel site surveys are not sufficient as the geographical scale is not sufficiently refined to detect focal transmission hotspots in low endemic areas. Targeted micro-mapping may be more suitable $[20,41,42]$, especially in areas that are ecologically diverse where the co-endemicity may vary and different diagnostic tools may be required. Better delineation of where the rapid antigen test for $W$. bancrofti can or should be used is important (e.g. in low risk $L$. loa areas) as they may help to identify regions that do not require MDA [13]. Equally, it will be important to identify areas where alternative $W$. bancrofti diagnostics may be more appropriate to use such as the antibody Wb123-based mono or biplex test, qPCR or microscopy (e.g. high risk $L$. loa areas). Further, it will also be important to distinguish between LF clinical manifestations and other diseases with similar clinical presentations, notably podoconiosis (or non-filarial lymphoedema), which appears to be endemic in some of these countries [23, 43]. Monitoring the impact of other interventions used in these areas will be critical. The widespread distribution of community-directed treatment with ivermectin (CDTI) for onchocerciasis control may have impacted $W$. bancrofti transmission as shown elsewhere [44, 45]. Similarly, the recent significant scale-up of vector control for malaria, primarily ITNs/ LLINs, which has reduced malaria prevalence [46], may have reduced $W$. bancrofti prevalence, as also demonstrated elsewhere [47, 48]. Revising the current WHO strategy for $L$. loa areas from MDA, to focus more on ensuring effective vector control, through ITNs/LLINs, integrating point-of-care test-and-treat options into health systems and consolidating closer links with the malaria control programme, may be a better use of the limited resources available for LF elimination programmes.

\section{Abbreviations}

CDTI: Community-directed treatment with ivermectin;

DEC: Diethylcarbamazine; DRC: Democratic Republic of the Congo; FTS: Filariasis test strip; GPELF: Global Programme to Eliminate Lymphatic Filariasis; ICT: Immunochromatographic test; LF: Lymphatic filariasis;
MDA: Mass drug administration; Mf: Microfilaria; NTDs: Neglected tropical diseases; qPCR: Quantitative real-time polymerase chain reaction; RAPLOA: Rapid Assessment Procedure for Loiasis; SAE: Severe adverse event; WHO: World Health Organization

Funding

LAKH acknowledges the support from the Department for International Development (DFID), and DHM support from Sightsavers, and the COUNTDOWN programme (grant ID is PO 6407) funded by UKAID part of the DFID, and GSK.

\section{Authors' contributions}

LAKH and DHM conceived the idea for the review. LAKH complied and analysed the data and wrote the first draft of the paper. All authors read and approved the final manuscript.

Ethics approval and consent to participate

Not applicable.

\section{Competing interests}

The authors declare that they have no competing interests.

\section{Publisher's Note}

Springer Nature remains neutral with regard to jurisdictional claims in published maps and institutional affiliations.

Received: 5 February 2018 Accepted: 14 May 2018

Published online: 15 June 2018

\section{References}

1. World Health Organization. Programmes and projects: Lymphatic Filariasis. Geneva: WHO; 2017. Available from: http://www.who.int/ lymphatic_filariasis/en/

2. Ichimori K, King JD, Engels D, Yajima A, Mikhailov A, Lammie P, et al. Global Programme to Eliminate Lymphatic Filariasis: the processes underlying programme success. PLoS Negl Trop Dis. 2014;8:e3328.

3. WHO. Summary of global update on preventive chemotherapy implementation in 2016: crossing the billion. Wkly Epidemiol Rec. 2017;92: 589-93

4. World Health Organization. Integrating neglected tropical diseases in global health and development: Fourth WHO report on neglected tropical diseases. Geneva: WHO; 2017. Available from: http://www.who.int/ neglected_diseases/resources/9789241565448/en/ .

5. Molyneux DH, Hopkins A, Bradley MH, Kelly-Hope LA. Multidimensional complexities of filariasis control in an era of large-scale mass drug administration programmes: a can of worms. Parasit Vectors. 2014;7:363.

6. Zouré HGM, Wanji S, Noma MM, Amazigo UV, Diggle PJ, Tekle AH, et al. The geographic distribution of Loa loa in Africa: results of large-scale implementation of the rapid assessment procedure for Loiasis (RAPLOA). PLoS Negl Trop Dis. 2011;5:e1210.

7. Chippaux JP, Boussinesq M, Gardon J, Gardon-Wendel N, Ernould JC. Severe adverse reaction risks during mass treatment with ivermectin in loiasisendemic areas. Parasitol Today. 1996;12:448-50.

8. Gardon J, Gardon-Wendel N, Demanga-Ngangue KJ, Chippaux JP Boussinesq M. Serious reactions after mass treatment of onchocerciasis with ivermectin in an area endemic for Loa loa infection. Lancet. 1997;350:18-22.

9. Weil GJ, Curtis KC, Fakoli L, Fischer K, Gankpala L, Lammie PJ, et al. Laboratory and field evaluation of a new rapid test for detecting Wuchereria bancrofti antigen in human blood. Am J Trop Med Hyg. 2013;89:11-5.

10. Bakajika DK, Nigo MM, Lotsima JP, Masikini GA, Fischer K, Lloyd MM, et al. Filarial antigenemia and Loa loa night blood microfilaremia in an area without bancroftian filariasis in the Democratic Republic of Congo. Am J Trop Med Hyg. 2014;91:1142-8.

11. Wanji S, Amvongo-Adjia N, Koudou B, Njouendou AJ, Chounna Ndongmo PW, Kengne-Ouafo JA, et al. Cross-reactivity of filariais ICT cards in areas of contrasting endemicity of Loa loa and Mansonella perstans in Cameroon: implications for shrinking of the lymphatic filariasis map in the Central African Region. PLoS Negl Trop Dis. 2015;9:e0004184.

12. Wanji S, Amvongo-Adjia N, Njouendou AJ, Kengne-Ouafo JA, Ndongmo WPC, Fombad FF, et al. Further evidence of the cross-reactivity of the Binax 
NOW Filariasis ICT cards to non-Wuchereria bancrofti filariae: experimental studies with Loa loa and Onchocerca ochengi. Parasit Vectors. 2016;9:267.

13. Pion SD, Montavon C, Chesnais CB, Kamgno J, Wanji S, Klion AD, et al. Positivity of antigen tests used for diagnosis of lymphatic filariasis in individuals without Wuchereria bancrofti infection but with high Loa loa microfilaremia. Am J Trop Med Hyg. 2016;95:1417-23.

14. World Health Organization. Provisional strategy for interrupting lymphatic filariasis transmission in loiasis endemic countries. Geneva: WHO; 2012.

15. Kelly-Hope LA, Stanton MC, Zouré HGM, Kinvi BE, Mikhailov A, Tekle A, et al. A practical approach for scaling up the alternative strategy for the elimination of lymphatic filariasis in Loa loa endemic countries - developing an action plan. Glob Health Res Policy. 2017;2:12.

16. Wanji S, Esum M, Jelil A, Mbeng A, Patrick C, Abong R, et al. Mapping of lymphatic filariasis in loiasis areas: a new strategy shows no evidence for Wuchereria bancrofti endemicity in Cameroon. 66th Annual Meeting of the American Society of Tropical Medicine and Hygiene. Baltimore; 2017.

17. Biholong B, Mbia P, Akame J, Moungui H, Ayissi G, Wanji S, et al. A significant step towards lymphatic filariasis elimination in Cameroon: the disease is not endemic in 31 health districts co-endemic with Loa loa and hypoendemic for onchocerciasis. 66th Annual Meeting of the American Society of TropicalMedicine and Hygiene. Baltimore; 2017.

18. Wanji S, Akotshi DO, Mutro MN, Tepage F, Ukety TO, Diggle PJ, et al. Validation of the rapid assessment procedure for loiasis (RAPLOA) in the Democratic Republic of Congo. Parasit Vectors. 2012;5:25.

19. Zouré HGM, Wanji S, Noma M, Amazigo UV, Diggle PJ, Tekle AH, et al. The geographic distribution of Loa loa in Africa: results of large-scale implementation of the Rapid Assessment Procedure for Loiasis (RAPLOA). PLoS Negl Trop Dis. 2011;5:e1210.

20. Brito M, Paulo R, Van-Dunem P, Martins A, Unnasch TR, Novak RJ, et al. Rapid integrated clinical survey to determine prevalence and co-distribution patterns of lymphatic filariasis and onchocerciasis in a Loa loa co-endemic area: the Angolan experience. Parasite Epidemiol Control. 2017;2:71-84.

21. Casaca VM. Contribution to the study of bancrofti filariasis in Angola. 1. Possibilities of its existence and probable distribution. 2. Bibliographic review and personal observations. An Inst Med Trop (Lisb. Portugal). 1966; 23:127-32. (In Portuquese)

22. Fain A, Elsen P, Wery M, Maertens K. Les filarioses humaines au Mayumbe et dans les regions limitrophes (République du Zaire). Evaluation de la densite microfilarienne. Ann Soc Belg Med Trop. 1974;54:5-34.

23. Deribe K, Beng AA, Cano J, Njouendo AJ, Fru-Cho J, Awah AR, et al. Mapping the geographical distribution of podoconiosis in Cameroon using parasitological, serological, and clinical evidence to exclude other causes of lymphedema. PLoS Negl Trop Dis. 2018;12:e0006126.

24. Drame PM, Montavon C, Pion SD, Kubofcik J, Fay MP, Nutman TB. Molecular epidemiology of blood-borne human parasites in a Loa loa-, Mansonella perstans-, and Plasmodium falciparum-endemic region of Cameroon. Am J Trop Med Hyg. 2016;94:1301-8.

25. Boussinesq M. La filariose lymphatique au Cameroun: état des connaissances. Le Bul. liaison documnetation I'OCEAC. 1999:34:7-12.

26. Sharp NA. Filariasis in Cameroon, with special reference to skn infections by microfilariae. Trans R Soc Trop Med Hyg. 1928:21:413-6.

27. Languillon J. Map of filaria of the Cameroons. Bull Soc Pathol Exot. 1957;50: 417-27. (In French)

28. Brengues J. La filariose de Bancroft en Afrique de l'Ouest Memoires. Paris: ORSTOM; 1975.

29. Lochouarn L. Action des régulateurs de croissance a doses sublétales sur des vecteurs de filarioses en Afrique Centrale. Thèse de Doctorat (spécialité : entomologie mé- dicale), Université Paris VI, France; 1990.

30. Hawking F. The distribution of Bancroftian Filariasis in Africa. Bull World Health Organ. 1957;16:581-92.

31. Galliard H. Recherches sur les filarioses au Gabon Occidental. Bull Soc Pathol Exot. 1932;25:167-74

32. Ouzilleau F. Human filariae in the region of M'Bomou (French Equatorial Africa). Pathology of elephantiasis in this region. The role of Filaria volvulus. Bull Soc Pathol Exot. 1913;6:80-8.

33. Kershaw WE. Demonstrations Liverpool School of Tropical Medicine Department of Tropical Medicine (Laboratory meeting). Trans R Soc Trop Med Hyg. 1953:47:1-12.

34. Kamgno J, Boussinesq M. Hyperendemic loaiasis in the Tikar plain, shrub savanna region of Cameroon. Bull Soc Pathol Exot. 2001;94:342-6. (In French)
35. Hawking F. The distribution of human filariasis throughout the World. Part IIl. Africa. WHO/FIL/74, vol. 124. Geneva: WHO; 1974. p. 1-38.

36. Hamon J, Burnett GF, Adam JP, Rickenbach A, Grjebine A. Culex pipiens fatigans Wiedemann, Wuchereria bancrofti Cobbold and the economic development of tropical Africa. Bull World Health Organ. 1967;37:217-37. (In French)

37. Brumpt LC, Sang HT, Jaeger G. Blood and intestinal parasitism in 2 central African villages. Bull Soc Pathol Exot. 1972;65:263-70. (In French)

38. Sasa M. Human filariasis - a global survey of epidemiology and control. Baltimore: University Park Press; 1976.

39. Richard-Lenoble D, Kombila M, Carme B, Gilles JC, Delattre PY. Prevalence of human filariasis with microfilaremia in Gabon. Bull Soc Pathol Exot. 1980;73: 192-9. (In French)

40. Molyneux DH, Mitre E, Bockarie MJ, Kelly-Hope LA. Filaria zoogeography in Africa: ecology, competitive exclusion, and public health relevance. Trends Parasitol. 2014;30:163-9.

41. Tekle AH, Zoure H, Wanji S, Leak S, Noma M, Remme JHF, et al. Integrated rapid mapping of onchocerciasis and loiasis in the Democratic Republic of Congo: impact on control strategies. Acta Trop. 2011;120(Suppl):S81-90.

42. Brant TA, Okorie PN, Ogunmola O, Ojeyode NB, Fatunade SB, Davies E, et al. Integrated risk mapping and landscape characterisation of lymphatic filariasis and loiasis in South West Nigeria. Parasite Epidemiol Control. 2018;3:21-35.

43. Deribe K, Cano J, Newport MJ, Pullan RL, Noor AM, Enquselassie F, et al. The global atlas of podoconiosis. Lancet Glob Health. 2017;5:e477-9.

44. Kyelem D, Sanou S, Boatin B, Medlock J, Coulibaly S, Molyneux DH. Impact of long-term ivermectin (Mectizan) on Wuchereria bancrofti and Mansonella perstans infections in Burkina Faso: strategic and policy implications. Ann Trop Med Parasitol. 2003;97:827-38.

45. Tekle AH, Zoure HGM, Noma M, Boussinesq M, Coffeng LE, Stolk WA, et al. Progress towards onchocerciasis elimination in the participating countries of the African Programme for Onchocerciasis Control: epidemiological evaluation results. Infect Dis Poverty. 2016;5:66.

46. Bhatt S, Weiss DJ, Cameron E, Bisanzio D, Mappin B, Dalrymple U, et al. The effect of malaria control on Plasmodium falciparum in Africa between 2000 and 2015. Nature. 2015;526:207-11.

47. van den Berg H, Kelly-Hope LA, Lindsay SW. Malaria and lymphatic filariasis: the case for integrated vector management. Lancet Infect Dis. 2013;13:89-94.

48. Nsakashalo-Senkwe M, Mwase E, Chizema-Kawesha E, Mukonka V, Songolo $P$, Masaninga $F$, et al. Significant decline in lymphatic filariasis associated with nationwide scale-up of insecticide-treated nets in Zambia. Parasite Epidemiol Control. 2017:2:7-14

\section{Ready to submit your research? Choose BMC and benefit from}

- fast, convenient online submission

- thorough peer review by experienced researchers in your field

- rapid publication on acceptance

- support for research data, including large and complex data types

- gold Open Access which fosters wider collaboration and increased citations

- maximum visibility for your research: over $100 \mathrm{M}$ website views per year

At BMC, research is always in progress.

Learn more biomedcentral.com/submissions 